\title{
Examining and Comparing the Economic Effects of Spillovers of Investment Risk in Iran: Computable General Equilibrium Model Approach ${ }^{3}$
}

\author{
SEYEDMASHHADI Pardis Alsadat ${ }^{4}$, JALAEE Seyed Abdolmajid ${ }^{5}$, \\ NEJATI Mehdi ${ }^{6}$, ZAYANDERODI Mohsen ${ }^{7}$
}

\begin{abstract}
Investment is as much as important for economic and social development that it is considered as one of the powerful levers for achieving the development. Accordingly, it is of great importance to assess the investment risk and its spillovers in all developed and developing countries because the risk phenomenon is one of the key features of decision making in the field of investment, affairs related to financial markets and a variety of economic activities. In this regard, the present paper evaluates the effect of investment risk spillover on key economic indicators using a computable general equilibrium model and the GTAP.9 database and the 2011 social accounting matrix (SAM) have been used for this purpose. Two scenarios of $10 \%$ and $3 \%$ increase in investment risk are considered in order to investigate the effect of these changes according to a recent trend analysis of economic indicators in Iran and the trend of the Iranian economy towards globalization and opening of the economy windows. The results show that both scenarios reduce investment risk, inflation, gross domestic product and total investment. Government expenditures are reduced in all sectors of the economy except for the service sector, which is almost unchanged. The exports are increased in all sectors and the imports are declined in sectors of agriculture, industry and services. As well as, the results show that the import of the oil and gas sector has not been heavily influenced by the investment risk due to its governmental status. By assessing these two scenarios and the sensitivity of the macroeconomic indicators to the degree of risk change, it can be stated that the key economic indicators will be significantly improved by managing the risk of investment; and the country will ultimately follow the development path more quickly.
\end{abstract}

Keywords: Risk spillover, Investment, Computable General Equilibrium Model

JEL: D58, F02

UDK: 005.334:330.322(55)

005.311:004

COBISS.SR-ID 253492492

\footnotetext{
${ }^{3}$ This paper is derived from the PhD thesis of Pardis Alsadat Seyedmashhadi, Kerman branch of Islamic Azad University, Kerman

${ }^{4}$ Kerman Branch, Islamic Azad University, Kerman, Iran

${ }^{5}$ Shahid Bahonar, University, Kerman, Iran, jalaee@uk.ac.ir

${ }^{6}$ Shahid Bahonar, University, Kerman, Iran

${ }^{7}$ Kerman Branch, Islamic Azad University, Kerman, Iran
} 


\section{Introduction}

Controlling and monitoring the financial risk have been considered by many businessmen, policy makers and financial market researchers in recent years. The main concern of the activists is related to the large incompatible movement in the market through financial risk monitoring. Extreme market dynamics indicate a huge movement of capital among market participants, in which the bankruptcy of some market participants will be inevitable. The presence of extensive communication between financial markets vindicates the monitoring and control of risk in various markets. In trade and exchanges between the two countries, as there are some spillovers such as technology and investment spillovers that could have beneficial effects for the country, it could also lead to spillover of risk, which such this could have adverse effects on the economic structure of the country. Risk spillovers in Iran's economy can affect the economy of the country through the oil and foreign exchange markets, but given the fact that these two spillovers result in spillovers of investment risk, the focus of the spillovers in this study are based on investment risk spillover. Global literature suggests that, generally, as technological and investment spillovers are from large economies to small economies, risk spillovers are also moving in the same direction. The research seeks to answer the following questions: (1) Do investment risk spillovers affect macroeconomic indicators in Iran? and (2) How much is the extent of the impact of risk spillovers on the indicators of inflation, production, government expenses, imports, exports, total investment, and the welfare index? To answer the questions, the framework of the article is presented in the way as follows: (1) The introduction; (2) The subject literature; (3) The theoretical foundations, (4) The model estimation; and in the end, (5) The conclusion.

\section{Literature}

Several studies have been conducted in the world literature and literature inside Iran about the subject matter of the paper, some of which are dealt with in this section.

$\mathrm{Du}$ and $\mathrm{He}$ (2015) have investigated the spillovers of extreme risks between crude oil and stock markets. Based on the method of Granger causality in risk, Value at Risk (VaR) is employed to measure market risk. Empirical results revealed that there are significant risk spillovers between the two markets.

Lin and Li (2015) have investigated both price and volatility spillover effects across natural gas and oil markets of US, Europe and Japan in a comprehensive VEC-MGARCH framework.

In all cases, the results support the presence of price spillover from crude oil markets to natural gas markets, but a reverse relationship does not exist. It was also found that the volatility in oil market seems to spillover to the natural gas market, and vice versa, in both US and Europe. On the contrary, volatility seems to be independent in natural gas and oil markets in Japan.

Shakeibaei and Teimori (2012) have applied new risk management tool, VaR methodology, and Granger causality test in risk to examine the risk spillover effect in both crude oil market and US dollar exchange market. Results have shown that, from the perspective of market risk, interaction between crude oil market and US dollar exchange rate does not seem strong.

Mc Dougall et al., (2012) in an article entitled General equilibrium mechanisms and the real exchange rate in the GTAP model have suggested that, because different economic sectors are interconnected, the impact of shock in one part of the economy can be found in another parts sight. According to the results of this paper, the initial increase in the exchange rate will increase exports and change the trade balance.

Jalaee et al., (2016) have examined the effects of the exchange rate shocks on investment and employment in Iran, using a CGE Model, based on the GTAP 8 dataset. The results have shown that the total investment in all areas examined is aligned with exchange rate changes.

Also, positive exchange rate shocks can increase overall employment rate. 
Heidari et al., (2017) have investigated macroeconomic and sectoral effects of labor immigration in Iran, applying a CGE model. The results have showed that both skilled and unskilled labor immigration, lead to reduction in economic growth, investment and capital return. This also reduces the production of various economic sectors.

Gharibnavaz and Waschik (2017) have detailed recent international sanctions against the Iranian economy and its government imposed by a subset of developed countries, using a CGE model. Their study has found, based on the GTAP 8 dataset, that international sanctions reduced aggregate Iranian welfare by $14 \%-15 \%$. The government of Iran sees a decrease in real revenue of $40 \%-50 \%$, due to the large negative effect of sanctions on the Iranian oil sector.

Phimister and Roberts (2017) have explored the importance of allowing for uncertainty in the magnitude of exogenous shocks in Computable General Equilibrium (CGE) models. The results have shown that the extent to which allowing for uncertainty can influence the magnitude of estimated impacts with some variables more sensitive to the uncertainty than others.

Farajzadeh et al., (2017) have developed a CGE model to study the potential welfare and environmental impacts of Iran's trade reform for accession to the World Trade Organization (WTO). The results have shown that removing trade barriers not only results in higher welfare and GDP as well as lower prices due to efficiency gains, but also reduces emissions of greenhouse gases in terms of $\mathrm{CO} 2$ equivalent.

\section{Theoretical foundation}

\section{Introduction of the GTAP A Multi Regional General Equilibrium Model (Nejati, 2012)}

The "Global Trade Analysis Project" model is a static model and does not include any dynamic effects of technological change, population growth and capital stock. Behavioral activities and inter-departmental and inter-regional exchanges consist of two components of the main equations consisting of accounting relationships and behavioral equations. The accounting relationships include the data available in the social accounting, data-output matrix tables, and behavioral equations indicate the behavior of economic factors in the model that relates to production, consumption, savings and regional investment. Its mathematical model consists of a set of nonlinear equations derived from the theory of microeconomic maximization by the Doug all method with accounting relationships. Each region consists of four economic factors, including the household representative of the region, private households, government, and enterprises. The regional household has the basic elements used in the production of enterprises.

The regional household income is the sum of the sales value of the production factors and the types of taxes and tariffs allocated these revenues to savings, the private household and the state based on a Cobb Douglas function. Private households and the government, having received income from the regional household, buy the goods and services they need from domestic and foreign markets. The demand for private households is evaluated based on the functional form of the Constant Difference Elasticity Function (CDE function), which was originally provided by Hanoch (1975); therefore, the private household demand will have a Non-Homothetic type, which, along with income changes, will not be a constant share of the cost of various goods in the household budget. The government's consumption demand functions are extracted using a Cobb Douglas utility function, which has a constant share of the cost of various goods. Firms use intermediate goods and, Factor inputs including labor, capital, land, and natural resources for the production of goods and services, and by combining these factors produce various types of goods and services. There are five factors of production, including land, skilled labor, unskilled labor, capital and natural resources. All factors, except for land and natural resources, are fully mobile across different sectors, but none of the factors of production is tradable or has international mobility. Selling these goods happens inside and outside of each region. Based on Standard Closure for the Global Trade Analysis Project, the production of all sectors, land, labor, capital and natural resources, and all prices are determined within the framework of the model or, in other words, are endogenous. The Numeracies in the 
"Global Trade Analysis Project" model is the world price index of primary factors, which is usually exogenous and is the weighted average of the price of the factors of production in all regions. It should be noted that depending on the type of research, it is possible to assume a different macro closures. Finally, the model is the percentage change, using the GEMPACK ${ }^{8}$ software (Harrison, Pearson, 1994) (Hertel et al., 1997).

In the general equilibrium model that can be calculated for the implementation and application of each scenario, a change is required in the model standard closure. In other words, the combination of the endogenous and exogenous variables of the model must be changed.

In addition, the number of functions must be equal to the number of unknowns so that the system can be solved. Therefore, the classification of variables in the closing of each model depends on the economic problem, in a way that is in line with the purpose and policy.

Moreover, this classification should have economic logic. Although users are free to choose the closure, it should be noted that the standard is the neoclassical global trade analysis project, so that all markets are in balance, the activity of all firms are under the premise of zero profit and the regional household on the budget line.

The first new function that is considered in the table and shows the effect of internal equilibrium on product changes is the function of the initial factors.

Qo $(i, r)=$ qocom $(i)+$ qoreg $(r)+$ qoall $(i, r)$

In function (1), qo (i, r) is the change percentage in the amount of product related to the initial commodity $i$ in the region $r$ and are determined by three primary factors that are normally exogenous in the standard GTAP. Adding this new function and primary shifter makes it easier to isolate the internal and external balance. These three primary factors in the regions $r$ and quall are the change percentage in the amount of the product related to the primary factor in the region $\mathrm{r}$.

The second new function introduces another closure variable, which is the total actual per capita consumption (uc) as the sum of government and private sector spending. It should be noted that for the separation of curves FE and BP, the variable uc is used. Adding a function to define this variable expresses its endogenousity in the GTAP standard closure.

AGGEXPAND (r). uc(r) = PRIVEXP (r). up(r) + GOVEXP (r). ug (r)

In function (2), uc(r), is the per capita consumption utility of the government and private sector in the region $\mathrm{r}$. This endogenous variable is divided into up(r) and $u g(r)$, which are the per capita consumption of the private sector and the government, respectively.

The two remaining variables that are effective in the closure are dpsave and pfactor(r). dpsave represents the growth rate of a part of the income that affects the savings distribution based on the savings function in the region $r$. Also, the change in dpsave affects the balance of investment-savings.

Psave (r)+ qsave (r)- y (r)=uelas (r)+dpsave (r)

In function (3), psave is the change percentage in the savings price in the region $r$, qsave (r) is the change percentage in regional demand for net savings, $y(r)$ is the change percentage in the regional household income in the region $r$, uels is the elasticity of the cost relative to the changes in desirability. dpsave ( $r$ ) is the savings distribution parameter.

The intended shock is applied by the variable pfactor which is the weighted average of the relative price of the production factors. This variable, which is an appropriate index to show the real exchange rate, is considered by the equations (4), (5) and (6) in the standard closure.

$$
V E N D W W L D \cdot \operatorname{pfactor}(r)=\sum_{i \in E N D-C O M}(V O M(i, r) \cdot p m(i, r))
$$

Function (4) calculates the percentage of changes in the primary price index in each region. In this function, pfactor( $\mathrm{r}$ ) is the primary market price index in the region $\mathrm{r}$ (average weight of the variety of production factors receivables), $\operatorname{VENDWWLD}(r)$ is the global value of the

\footnotetext{
${ }^{8}$ General Equilibrium Modeling Package
} 
primary factors, VOM $(i, r)$ is the value of the product $i$ in the market price in the region $r, p m$ $(i, r)$ is the market price of the commodity $i$ in the region $r$.

Equation (5) specifies the actual return rate of the primary factor $\mathrm{i}$ in the region $\mathrm{r}$.

Pfactorreal $(i, s)=p m(i, s)-\operatorname{ppriv}(s)$

In function (5), pfactorreal (i, r) is the difference between the rate of return of the primary factor i from the growth rate CPI (Consumer Price Index), pm (i, s) is the market price of the factor $\mathrm{i}$ in the region $\mathrm{s}$, pprive(s) is the price index for the private sector's consumption expenditure.

The function (6) calculates the percentage of change in the global price index of the primary factors.

VENDWWLD.pfactwld $=\sum_{r \in R E G}(\operatorname{VENDWrEG(r).pfactor}(r))$

In function (6), pfactwld is the percentage of change in the global price index of the primary factors.

$V E N D W W L D=\sum_{i \in E N D-C O M M}(V E N D W r E G(r)$

$\mathrm{n}$ function (7), VENDWREG(r), the value of the primary factors for the market price in each region, is obtained endogenously through function 8.

$\operatorname{VENDWrEG}=\sum_{i \in E N D w-C O M M} \operatorname{VOM}(i, r)$

In the standard closure of the global trade analysis project model, qoreg and dpsave are exogenous; while pfactor and uc(r) are defined endogenously. On the other hand, the curve FE and BP are analyzed through the relationship between consumption and real exchange rate. Hence, the exogeneity of consumption and the real exchange rate in the model are essential. To apply these modifications, you also need to change the model closure; so that the transition parameters are endogenous. So, using the replacement functions, consider uc exogenous and dpsave endogenous; so that these functions enable the model to change the total savings. It also makes pfactor exogenous and qoreg endogenous so that makes it possible to change at the level of the primary factors.

The labor is one of the primary factors behind which price has been changed followed by the exogenous changes of pfactor in this study. In the general equilibrium model, demand and supply of labor are determined, respectively, by the regional firm and household. Therefore, according to equations (9) and (10), the demand and supply of this factor and employment in general are affected.

Qfe $(i, j, r)=-a f e(i, j, r)+$ qva $(j, r)-\operatorname{ESUBVA}(j) *[p f e(i, j, r)-a f e(i, j, r)-p v a(j, r)]$ (9)

In Equation (9), qfe (i, j, r) are the demand for the factor $i$ in the section $j$ and the region $r$, afe $(i, j, r)$ is the technical progress related to factor $i$ in the section $j$ and the region $r$, pva $(j, r)$ is the value-added price of the firm in section $\mathrm{j}$ in the region $\mathrm{r}, \mathrm{pfe}(\mathrm{i}, \mathrm{j}, \mathrm{r})$ is the price of production factor $\mathrm{i}$ in section $\mathrm{j}$ and the region $\mathrm{r}$.

ps (i, r) to (i, r) pm (i, r)

In equation (10), ps $(\mathrm{i}, \mathrm{r})$ is the supply price of the primary production factor $\mathrm{i}$ in the region $r$, to $(i, r)$ is the tax on the supply of the primary factor and pm (i, r) is the market price of the factors. With the change in regional household income, one of the ways to achieve it, is the sale of primary production factors, savings will also change. On the other hand, in the GTAP model, according to Walras law, savings and investment are equal. So, looking to change the regional household income, investment will also change. Equations (11) and (12) illustrate how the regional household income changes, following the change in the price of the primary factors of production, and the allocation of that income between private consumption expenditure, government, and savings.

$\mathrm{FY}(\mathrm{r}) *$ fincome $(\mathrm{r}) \operatorname{VDEP}(\mathrm{r}) *[\operatorname{pcgds}(\mathrm{r})+\mathrm{kb}(\mathrm{r})]$

$$
\Sigma_{\text {ENDWMENT }} \operatorname{VOM}\left(i_{s}, \mathrm{r}\right) *\left[\mathrm{pm}\left(\mathrm{i}_{s} \mathrm{r}\right)+\mathrm{qo}\left(\mathrm{i}_{s} \mathrm{r}\right)\right]
$$


$\mathrm{FY}(\mathrm{r})$ is the net income from sales of the production factors in the region $r$, fincome(r) is the growth rate of FY. Vom $(i, r)$ is the value of selling the factors of production to the market price, qo (i, r) is the amount of the supply of factor $i$ in the region $r, \operatorname{VDEP}(r)$ is the value of depreciation of capital in the region $\mathrm{r}$. $\mathrm{kb}(\mathrm{r})$ is the growth rate of the beginning capital stock in the region $r$ and $\operatorname{pcgds}(r)$ is the price of capital goods.

Regional household income is distributed on the basis of a Cobb-Douglas function, between private households, government and savings. Therefore, the regional household demand system is expressed in accordance with Equation (12).

$\operatorname{dpav}(r)=\operatorname{XSHRPRIV}(r) * \operatorname{dppriv}(r)+\operatorname{XSHRGOV}(r) * \operatorname{dpgov}(r)+\operatorname{XSHRSAVE}(r) * \operatorname{dpsave}(r)$ (12)

$\operatorname{dpav}(r)$ is the average transmission of distribution parameter in the region $r$, XSHRPRIV (r) is the share of private households cost in total cost (or total regional household income), $\mathrm{XSHRGOV(r)}$ is the share of government expenditure. XSHRSAVE(r) is the savings share, dpprive( $\mathrm{r}$ ) is the private household consumption distribution parameter, $\operatorname{dpgov}(\mathrm{r})$ is the government consumption distribution parameter and dpsave(r) is the saving distribution parameter in the region $r$.

\section{Modeling risk}

We assume that the global bank equalizes expected risk-adjusted rates of return, so that riskadjusted rates for all regions are equal to some global average.

RORE(r)/RISK(r) = RORG

Where, in accordance with GTAP notation convention, these capitalized variables represent levels, while lower-case variables represent percentage rates of change from initial levels.

RORE(r) is a non-risk-adjusted expected rate of return, i.e. it is the expected rate of return in the absence of any default by the borrower.

RISK(r) represents the ratio of equilibrium returns in region $r$ to the global average rate of return. For relatively high-risk countries, this ratio will be above 1, and for relatively safe countries below 1 . It is important to note that this variable represents a ratio rather than a certain number of basis points - it is better called a "risk ratio" than a "risk premium".

RORG does not represent a risk-free return but a weighted average of returns around the world. This formulation differs from the more familiar representation of required rate of return in a country being equal to the risk-free return plus some risk margin.

If we rewrite this as

$\operatorname{RORE}(\mathrm{r})=\mathrm{RORG} * \mathrm{RISK}(\mathrm{r})$

Then by total differentiation and division through by RORE(r) we can obtain $\operatorname{rore}(\mathrm{r})=\operatorname{rorg}+\operatorname{risk}(\mathrm{r})$

where these variables are percentage changes in their levels equivalents. This is

the analogue of equation (11') in the standard GTAP model in the case where RORDELTA $=1$ :

rore $(\mathrm{r})=\operatorname{rorg}+\operatorname{cgdslack}(\mathrm{r})$

This equation states that the percentage change in the rate of return on investment in region $r$ is equal to the percentage change in the global rate of return plus a disequilibrium factor which is generally exogenous and set at zero in a general equilibrium closure. Normally, the cgdslack variable is only non-zero when we allow disequilibrium to exist in the market for capital goods.

The main proposition of this paper is that cgdslack can be interpreted to represent a risk premium as defined above, although it was not originally designed for this purpose. In a general equilibrium closure, cgdslack is unused for any other purpose (being exogenous and unshocked), and therefore we do not disturb any other components of the model by using it in this way. 


\section{Model estimation}

In this study, the criterion of risk spillover and its channel is investment. Given that one part of the investment comes from external sources, it can transfer the risk from the outside to the other or from part to the other. In this study, the effect of spillover risk is studied on the indicators firstly affected by risk and, secondly, these indicators can affect other variables.

\section{Aggregate gtap data}

Data in GTAP is introduced AS 8 production factors, 57 sectors and 140 regions. In this research, the information is in the form of the 2011 Social Accounting Matrix, which uses the latest version of GTAP (www.gtap.agecon.purdue.edu/databases/v9/default.asp). The model database contains the values of all exogenous variables and parameters and the equilibrium values of the endogenous variables. Estimation of the model was done using the GEMPACK software package (Harrison and Pearson, 1994). In Table 1, details of sectors, regions, and factors of production in this paper are presented. The reason why we did not differentiate other countries in the region is that Iran is economically a small country, which is why creating investment risk in the Iranian economy would not affect other regions such as the European Union, the United States, the Middle East, etc. very much affected.

Table 1. Model Details

\begin{tabular}{|c|c|}
\hline Aggregate & Subset \\
\hline Sectors & Agriculture, Oil and Gas, Industry, Services \\
\hline Regions & Iran, Rest of world \\
\hline production factors & Labor, Capital, Land, Natural Resources \\
\hline
\end{tabular}

The scenarios in this study are two scenarios of an increase of $10 \%$ and $3 \%$ of investment risk. In each of these scenarios, we will deal with the analysis of the effects of the investment risk on inflation, GDP, government expenditures, imports, exports, total investment and the welfare index quantitatively calculated using the global trade Computable General Equilibrium Model.

\section{First scenario: $10 \%$ increase in investment risk spillover}

In this scenario, we consider $10 \%$ of the imported risk based on the past trend of the Iranian economic system, which, of course, can be achieved by using the $\mathrm{VaR}^{9}$ method.

Considering the statehood of the Iranian economy and the role played by open economics in the country, government spending imports and exports has examined by economic sector. As Table 2 shows, the spillover of investment risk has had a negative impact on government spending related to agriculture, oil and gas and industry, with the largest share of agriculture, oil and gas sectors. This is due to the agricultural sector because of the alternative role for the government and contributing to the oil and gas sector. Nevertheless, the service sector inherently has not only been negatively affected, but also positive, due to sluggish changes. One of the reasons is that the activities of this sector are more applied.

Shocked, imports in agriculture, industry and services have declined. Given that about 85 percent of Iran's imports are intermediate and capital goods, as well as agricultural and industrial sectors are dependent on imports of these types of goods; therefore, due to the shrinking investment, the import volumes of these sectors due to the decrease in the ability to buy them will be reduced. However, the oil and gas sector has not only diminished, but also increased due to its oil revenues and government spending. The service sector, like the industrial and agricultural sector, has been less able to buy and, as a result, has decreased its imports.

${ }^{9}$ Value at Risk 
Exports have increased in all sectors as these sectors compensate for investment-related shortages in investment through increased exports. On the other hand, the effect of investment on exports will take place over a long period. The reason why the increase in exports in the oil and gas sector is lower than in other sectors is that the oil and gas sector is a public sector and less under the influence of investment.

Table 2. The results of a $10 \%$ increase in investment risk on Government Expenditure, Imports, Exports (percent)

\begin{tabular}{|c|c|c|c|c|}
\hline & Agriculture Sector & Oil and Gas Sector & Industry Sector & Service Sector \\
\hline Government Expenditure & -2.15 & -2.55 & -1.92 & 0.06 \\
\hline Imports & -3.99 & 0.79 & -5.53 & -5.57 \\
\hline Exports & 10.17 & 1.34 & 11.43 & 9.58 \\
\hline
\end{tabular}

Resource: Researcher finding

As shown in Table 3, with a $10 \%$ investment risk shock, inflation dropped to $2.02 \%$. Given the indirect relationship between risk and investment, the risk involved will reduce the investment that stimulates the demand side of the economy, thereby affecting the demand side of the economy and therefore has a negative impact on inflation.

GDP declined by $0.34 \%$. The reason is that in the Iranian economy, because of the government's economy and the high share of the state in the economy, production is more based on sectors that are state-owned. Therefore, the overwhelming impact of the risk of investment by the nongovernmental sector on production is diminishing, but this decline is not very significant due to the higher share of the government.

The total investment dropped to 7.76 percent, which is quite natural because there is always a significant and indirect relationship between investment risk and amount of investment.

Reducing investment is more likely to decrease other indicators, and the reason is that the impact of spillover risks directly on investment itself. Therefore, considering that the impact of spillover of investment risk on the investment is negative and also negatively affects the main sectors of the economy, including the agricultural sector, the welfare index also decreases. As investment through government expenditures as well as imports has negative effects on agricultural and industrial sectors and, on the other hand, much of the population is dependent on these two economic areas, and the welfare index is directly related to people's lives; therefore, the total welfare decreased 757.14 million dollars.

Table 3. The results of a $10 \%$ increase in investment risk on Inflation, GDP, Total Investment (percent) And Welfare Index (million dollar)

\begin{tabular}{|c|c|c|c|c|}
\hline & Inflation & GDP & Investment & Welfare \\
\hline Iran & -2.02 & -0.34 & -7.76 & -757.14 \\
\hline Rest of world & 0.01 & 0 & 0.04 & 515.35 \\
\hline \multicolumn{5}{|c|}{ Resource: Researcher finding }
\end{tabular}

\section{Second scenario: $3 \%$ increase in investment risk spillover}

In this scenario, we reduced the risk from 10 to 3 percent to know if the sensitivity of the research indicators to degree of risk change is significant.

As shown in Tables 4 and 5, sectors firstly show a large response in the same direction, and secondly, determine how much modulation policies in the area of investment risk can affect making decisions on the effect of investing in economic sectors. Therefore, adjusting the risk index can substantially modulate the sectors of GDP, government spending, inflation, imports, exports, total investment, and welfare. 
Table 4. The results of a 3\% increase in investment risk on Government Expenditure, Imports, Exports (percent)

\begin{tabular}{|c|c|c|c|c|}
\hline & Agriculture Sector & Oil and Gas Sector & Industry Sector & Service Sector \\
\hline Government Expenditure & -0.69 & -0.81 & -0.61 & 0.01 \\
\hline Imports & -1.28 & 0.24 & -1.75 & -1.79 \\
\hline Exports & 3.11 & 0.44 & 3.47 & 2.9 \\
\hline
\end{tabular}

Resource: Researcher finding

Table 5. The results of a 3\% increase in investment risk on Inflation, GDP, Total Investment(percent) And Welfare Index (million dollar)

\begin{tabular}{|c|c|c|c|c|}
\hline & Inflation & GDP & Investment & Welfare \\
\hline Iran & -0.64 & -0.11 & -2.42 & -243.48 \\
\hline Rest of world & 0 & 0 & 0.01 & 167.54 \\
\hline \multicolumn{5}{|c}{ Resource: Researcher finding }
\end{tabular}

\section{Conclusion}

As regards today's world moves towards to open more economy doors and the process of globalization occurs with greater acceleration, that one of the factors resulted from the process of globalization on the economies, that is discussing risk spillover. The risks spill from different regions of the world to a country or a region. This research was looking for the answer to these questions; that 1- Do the investment risk spillover influence macro-economic indexes in Iran? And, 2- How and how much are the impact of risk spillover on the indexes of inflation, production, government spending, import, export, total investment, and welfare index?

It was done the proper estimated to answer the two questions of the research, which the results have shown that the existence of the original economic variables of the investment risk have influenced the cases such as the inflation, gross domestic product, government spending, import, export, total investment, and the welfare index. Due to the existence of the alternative role between the government spending and the investment, so it has negatively affected different economic sectors by creation of investment risk. It reduces the inflation and grass domestic production and because the total investment is directly under the influence of investment risks, it has reduced greatly.

Welfare, which is a function of income and the prices; by reducing the amount of investment because of the risk, and followed by reducing the level of real prices and the reduction of real income led to decrease the income of private households and this led to reduced private consumption by them and so, the total welfare is reduced. With arisen shock, the import of all economic sectors except for the rock oil and gas sector have been reduced, because this section is completely state-owned. In return, the export has increased in all sectors.

This study, in order to measure the sensitivity of indexes towards the risk variable has studied the impact of risk spillover on the desired variables of the research in two scenarios of 3 and 10 percent. It has concluded that, firstly, the main indexes of the economy react towards the change of the risk extent, and secondly, their sensitivity is remarkable. So, if in the economic system of Iran, the risk extent be managed, then the macroeconomic indexes will show notable reaction towards improving.

\section{REFERENCES}

1. Du, L., He, Y. (2015). Extreme risk spillovers between crude oil and stock markets. Energy Economics. Vol 51: 455-465.

2. Farajzadeh, Z., Zhu, X., Bakhshoodeh, M. (2017). Trade reform in Iran for accession to the World Trade Organization: Analysis of welfare and environmental impacts. Economic Modelling. Vol 63: 75-85.

3. Gharibnavaz, M.R., Waschik, R. (2017). A computable general equilibrium model of international sanctions in Iran. The world economy. Vol 40. 
4. Heidari, H., Davoudi, N., Talebi, F. (2017). Macroeconomic and sectoral effects of labor immigration: application of CGE model. Research and Planning in Higher Education. Vol 4: 2542.

5. Hertel, T.W., Tsigas, M.E. (1997). Structure of GTAP, in T.W. Hertel (ed.), Global Trade Analysis; Modeling and Applications. Cambridge University Press.

6. Jalaee S.A., Nejati, M., Bagheri, F. (2016). Examining the effects of the exchange rate shocks on investment and employment in Iran, Using a Computable General Equilibrium Models. The Economic research of Iran. Vol 16: 201-220.

7. Lin, B., Li, J. (2015). The spillover effects across natural gas and oil markets: Based on the VEC-MGARCH framework. Applied Energy. Vol 155: 229-241.

8. Malcolm, G. (1998). Modeling country risk and capital flows in GTAP. GTAP Technical Paper No. 13.

9. Mc Dougall, R., Akgul, Z., Walmsley, T., Hertel, T., Villoria, N. (2012). General equilibrium mechanisms and real exchange rate in the GTAP model. Third Draft of a Technical Document: $1-40$.

10. Phimister, E., Roberts, D. (2017). Allowing for uncertainty in exogenous shocks to CGE models: the case of a new renewable energy sector. Economic Systems Research: 1-19.

11. Shakeibaei, A., and Teimori, E. (2012). Risk spillover effect of US dollar exchange rate on oil prices. The Economic research of Iran. Vol 12: 99-121.

\section{Article history:}

- $\quad$ Received 20 September 2017

- $\quad$ Accepted 1 December 2017 